Administrative Issues Journal: Connecting Education, Practice, and Research, Summer 2018, Vol. 8, No. 1: 48-58. DOI: 10.5929/2018.8.1.3

\title{
Developing the capacity of culturally competent leaders to redress inequitable outcomes: Increasing opportunities for historically marginalized students
}

\section{Sheri Williams, Ed.D. University of New Mexico}

\begin{abstract}
Objective: This study investigated the practices and impact of interdisciplinary faculty at a flagship university in the American Southwest who were engaged in the process of redesigning curriculum in order to center candidates on what they need to know and do as culturally competent school leaders.

Method: Participants were 31 interdisciplinary faculty involved in preparing candidates for leadership in early childhood and elementary and secondary education, in diverse contexts including high need and Native American-serving schools. The qualitative study utilized document analysis of faculty's multi-year work in developing the capacity of candidates to increase opportunities for historically marginalized students. An external evaluation was conducted with focus groups of faculty and graduate students along with a follow-up discourse analysis of student reflective journals.

Results: The redesign process involved several phases culminating in recommendations and next steps for preparing candidates to redress inequitable conditions and create a more hopeful future for America's diverse students.

Conclusions: Developing the capacity of culturally competent leaders requires a fundamental change in the way institutions prepare candidates for equity and social justice work. Further research is needed to demonstrate that recommended activities and interventions will improve the cultural competence of educational leaders and make opportunity equity a reality for all children.
\end{abstract}

Keywords: cultural competence, curriculum redesign, educator preparation, school leaders, ESSA

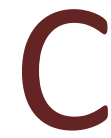

all to Action. The Every Student Succeeds Act (ESSA) sets the course for a new kind of accountability for school and system leaders. ESSA promises to end the overly prescriptive tactics of No Child Left Behind (NCLB) and provide more flexibility for schools to design their own improvement strategies. States are now required to redesign their plans in consultation with appropriate state officials, teacher representatives, local education agencies, representatives of Indian Tribes, community-based organizations, families, and others (ESSA, 2015). The new state systems took effect beginning in the 20172018 school year. Civil rights advocates noted ESSA is a "first step toward ensuring that all students are 
counted, and that parents and communities can hold their schools accountable for meeting the needs of their students" (Leadership Conference on Civil and Human Rights, 2016, para. 2).

ESSA sounds an urgent call to build the capacity of district and school leaders who are prepared to improve outcomes for historically marginalized students. Developing leaders with the capacity and grit to intervene and turnaround inequitable outcomes for underrepresented children and youth is urgent work. Aspiring school leaders must be prepared to tackle the entrenched inequalities that keep students of color, students with disabilities, students whose home language is other than English, and students living in poverty from graduating high school on time and gaining access to college and career success (Jensen, 2009; U. S. Commission on Civil Rights, 2018).

Institutions of higher education are especially challenged to provide intensive leadership development that better prepares aspiring administrators to boost the academic achievement and wellbeing of struggling students. Reimagining the way school leaders are prepared is crucial to making a noticeable difference in this unprecedented era of inequality. There is little argument that widespread disparities continue to exist. There are too many children in this country who attend schools marred by widening opportunity gaps, language and cultural bias, disproportionate rates of suspension and expulsion among children of color, school resegregation, chronic absenteeism, and bullying and violence (Balfanz \& Byrnes, 2012). Too many children suffer from childhood trauma, homelessness, food insecurity, acute health issues and disabilities, and incarceration in the juvenile justice system (Morgan, Salomon, Plotkin, \& Cohen, 2014).

The inclusion of new language in ESSA reflects the increasing awareness that America will not achieve its vision of excellence without equity. Under ESSA's new language, states and districts are required to report, pursuant to section 203(c)(1) of the Department of Education Organization Act (20 U.S.C. 3413(c)(1)): measures of school quality, climate and safety, including rates of in-school suspensions, out-of-school suspensions, expulsions, school-related arrests, referrals to law enforcement, chronic absenteeism (including both excused and unexcused absences) and incidences of violence, including bullying and harassment.

Consequently, it is imperative that educational leadership faculty take steps to redesign programs of study that build leader capacity to serve in high-needs schools where accountability and intervention for equity and social justice is a priority (Costa, 2015). Meeting the challenges and opportunities of ESSA suggests that faculty start by reimagining preparation programs in a way that would better prepare culturally competent candidates for equitable and socially just leadership in demographically changing schools (Cooper, 2009; Shields, 2013).

\section{Theory of Action and Research Questions}

Over a multi-year period, scholars in the college of education at a flagship university in the American Southwest engaged in thoughtful scholarship on redressing inequitable outcomes through redesigned curriculum and pedagogy that centered on cultural competence and inclusivity. Faculty embarked upon the redesign process with an explicit theory of action (Starratt, 1991); that is, if a group of interdisciplinary faculty came together to address the critical importance and value of revising curricular and pedagogical stances that center candidates on what they need to know and do as culturally competent leaders, then graduates would be better prepared to take action to redress inequitable outcomes and increase opportunities for historically marginalized students. 


\section{Research Questions}

Question 1: What happens when faculty engage in a multi-year interdisciplinary study to redesign the preparation of the next generation of educational leaders?

Question 2: What should be the desired knowledge base for culturally competent leaders?

Question 3: What pedagogy and interventions are needed to move pre-service candidates to the next level of cultural competence?

\section{Methodology: The Redesign Process}

Participants were 31 interdisciplinary faculty involved in preparing candidates for leadership in early childhood and elementary and secondary education, in diverse contexts including high need and Native American-serving schools. The qualitative study utilized document analysis of the faculty's multi-year work in developing the capacity of pre-service candidates to redress inequitable outcomes and increase opportunities for historically marginalized students. Faculty were surveyed on their perceptions regarding their collaboratively-developed definition and indicators of cultural competence. An external evaluation was conducted with focus groups of faculty and graduate students along with a follow-up discourse analysis of student reflective journals.

What follows is a discussion of the phases of the multi-year study involving redesign of the curriculum, pedagogy and interventions. The interdisciplinary work involved faculty across the disciplines of teacher education, educational leadership and policy; language, literacy and sociocultural studies; individual, family, and community education; education specialties; art education; Native American studies; and health exercise and sports sciences.

Phase 1 started with organizing time and talents to launch the work. Phase 2 consisted of activities focused on building the capacity of interdisciplinary faculty through intentional collaboration with educators and community members. In phase 3, faculty began the important work of co-creating a definition of, and indicators for, cultural competence in their unique contexts. In phase 4, faculty shared how they were redesigning course experiences to support the development of culturally competent leaders. Phase 5 culminated with an evaluation of the impact of the redesign work.

\section{Research Question 1: Faculty Engagement in the Redesign Process}

Phase 1: Organizing for Collective Work. Phase 1 began the dialogue. This phase involved a close examination of the reasons to embark on the redesign process. Faculty identified who would be involved and described how participants would create and share new knowledge and insights. During the planning phase, faculty members examined best practice research and their own experiences in light of the strategies and activities needed to advance the cultural competence of aspiring educators.

New perspectives and fresh knowledge emerged as faculty came together as thought partners to address how they might redesign and transform curriculum, leadership practices, and internship experiences in the preparation of the next generation of teachers, leaders and administrators. This phase involved participation as a community of learners in reading and discussing materials from collective areas of expertise and assisting in the development of a theoretical, operational and instructional framework for the group's work. 
Phase 2: Examining Capacity for Cultural Competence. Phase 2 extended opportunities for faculty to collaborate with community members to gain an appreciation of the community's languages, cultures, geographies, and histories. Faculty participated in local and regional visits to branch campuses, listened to elders and gathered the best hopes of community members in high-need urban, rural and tribal areas. The visits to local community sites provided participants with opportunities for joint curriculum development and activities. Using Ed Web, faculty shared reflections on how this type of community engagement would impact curriculum, clinical practices, and their own interdisciplinary research.

\section{Research Question 2: Developing a Knowledge Base for Culturally Competent Leaders}

Phase 3: Defining Cultural Competence and Key Indicators. In this phase, participants embarked on a study of what cultural competence meant to them, how they would define it for aspiring educators, and what they would name as the key indicators that candidates need to know and do to operate in the diverse environment of the schools. Small groups of what came to be known as Transformative Action Groups (TAG) suggested key indicators. A leadership team prepared a synthesis of the recommendations for presentation, revision and adoption at a TAG Retreat using the Focusing Four Consensus Strategy (Garmston and Wellman, 1999, p. 215-216).

What emerged was a draft definition of cultural competence and key indicators that participants agreed were generalizable across interdisciplinary areas of study. Faculty developed a definition of, and basic indicators for, cultural competence that they hoped could be used to help candidates make meaning for themselves, challenge their own practices, and, ultimately, see themselves as culturally proficient leaders. It was hoped that the definition and indicators would fairly represent a catalog of targeted possibilities that could be infused across the disciplines.

The definition and key indicators framed the basis for identifying what candidates needed to know and be able to do upon program completion. The indicators selected were consistent with a compelling body of cross-sector literature and reflected the wisdom of Blankstein, Noguera and others who posited that culturally competent leaders must root the work in their own commitment and face the data and their fears with an unwavering focus on equity and social justice (Blankstein, Noguera, Kelly, \& Tutu, 2015). The responsibility of school leaders to make equitable and culturally responsive decisions was further elevated by incorporating elements of Standard 3 of the Professional Standards for Education Leaders (National Policy Board for Educational Administration, 2015).

Faculty were surveyed on their perceptions regarding whether their collaboratively- developed definitions and indicators were observable and actionable. This involved an individual reflection on the extent of each member's agreement with the definition and indicators, the usefulness of the indicators as evidence/artifacts of candidate progress in cultural competence, and whether the indicators were precise enough to minimize differences in interpretation by instructors, clinicians and external evaluators. Appendix 1 provides a sample of a completed individual reflection sheet.

The work on the definition and indicators of cultural competence tended to reinforce faculty beliefs and values that, at its heart, redesigned curricula should promote engaged participation, ensure equity and build capacity for inclusivity. This meant integrating cultural proficiency into programs of study - even if the work created discomfort for some. The work required faculty to suspend their own ethnocentric views in order to begin to understand one another.

Phase 4: Redesigning Curriculum and Pedagogy. In phase 4, faculty presented the products they co-designed to bring about the intended changes for a more culturally infused and proactive curriculum. The products reflected learnings from the interdisciplinary work of the TAGs and demonstrated how 
faculty were working together to revisit decisions about curricular choices and pedagogy in a way that would promote deeper levels of thinking, collaboration, and engagement as culturally competent leaders. Faculty took the lead in developing coursework and clinical experiences. The products were designed to expand the way aspiring educators look at, assess, and understand the culture, tone, and climate of socially just and equitable schools (Boyd, 2008).

One product focused on building the skills and knowledge needed by leaders to make better decisions by examining low-inference data and becoming aware of cultural and other biases (Senge, 1994). Another product targeted equity resources that would elicit candidates' personal experiences, social presence/connectedness, and co-creation of new knowledge around critical cultural consciousness. And yet another product involved a case study to deepen students' ethnic/cultural understandings and practices, and prompt students' relevant historiesand social capital (Gray, 2011; Valdez \& Lugg, 2010; Yosso, 2005). In all, the products represented a broad collection of relevant scholarly readings and background experiences that promised to build the capacity of professional educators to create and sustain culturally responsive school systems. Approaches to the work included Paulo Freire's problemposing method (1998), LatCRT, and IndigenousCRT.

In the end, participants speculated that a redesigned curriculum would provide candidates with frequent practice in examining their culturally competent leadership dispositions, understandings and practices. The ultimate goal of the redesign work was to continuously assess, revise, and redesign curriculum and pedagogy that would result in growth/gains in candidates' cultural competence.

\section{Research Question \#3: Interventions to Develop Cultural Competence}

Phase 5: Evaluating the Impact of the Redesign Work. Faculty wanted to know if their interventions were making a difference in overall program coherence and impact. They speculated that simply emphasizing the tenets of cultural competence in coursework would not guarantee that candidates would be able to enact them in their future positions. The Principal Investigator engaged the services of an external evaluator to judge the merit and work of the redesign process utilizing funding from the W. $\mathrm{K}$. Kellogg foundation. McREL International was secured to collect data from faculty and focus groups with students who were enrolled in the preparation programs. Contextually-relevant findings were then presented to the faculty.

Focus groups were asked to what extent their coursework and activities helped them develop cultural competencies and to what extent they understood and were prepared to display relevant cultural competencies. Participants described their work as a calling that would build their capacity to serve others in their respective communities:

I think for many of us here in the group... we realize it's a calling. It's not something that I chose to do... It's something that I've been called to do for my people, and who am I to say no?

Other focus group participants explained that they had experienced inequalities in school systems-both as students and as educators. These individuals indicated that they planned to leverage what they learned in the educational leadership program to bring cultural sensitivity to schools and make educational experiences more meaningful and challenging:

For me, it was the inequities as a student coming from a school system that wasn't culturally sensitive or culturally relevant in its curriculum. I think that in itself was also a calling to what are the injustices that are happening in my own community in regard to the ideologies that happen in the classrooms. 
Many participants commented positively on the efforts made by instructors to learn about communities and provide culturally-relevant instruction:

I think the professors did a really good job of coming out to our communities for different events. I know they had something in [city]. They came out to [city] and I think they did something at the... Center. I like that they made that attempt to visit the communities... and then extend an invitation to us to go meet with them.

I think they tried to stress that when we do our assignments... The feedback we do get is, how does this relate to your cultural norm or where you're at in that, what is the relevance, and how can you relate it back?

As candidates explored culturally-rooted methods, they tended to focus on finer details about what is important in modeling and demonstrating cultural competency in their coursework and at their own school sites. One focus group participant recognized the importance of modeling the act of listening responsively and responsibly to discern and integrate multiple perspectives and ways of communicating experiences, contributions, histories and geographies.

Phase 5: Follow-up. As a follow-up to the external evaluation, a purposefully selected cohort of aspiring administrators who consented to be involved in the inquiry were asked if the definition and indicators were understandable and useful for their own study and future work. Participants were educational leadership students in a fast-track post-graduate certificate program for administrator licensure. They engaged in a reflective journal exchange with the instructor that was designed for selfreflection and collaborative critique (Neufeld \& Roper, 2003; Saleh, McBride, \& Henley, 2006). Samples of students' reflective journaling along with instructor interventions are provided in Table 1.

Table 1

Sample Reflective Journal Exchange

Candidate reflection

"The Cultural Competencies stretched my knowledge of things that the leader can do to promote a healthy school culture, in that I never really thought about how many things contribute to that. I especially appreciated the way that they are stated and are broken down into concrete expectations of the leader. They begin with verbs, which make them all actionable."

\section{Instructor intervention}

"What would you add, delete, or change that would further contribute to your mission to promote a healthy school culture?"
"I think these [competencies] are things that school leaders should continually reflect upon, until they are ingrained and a part of the leader's daily way of doing things at school."
"Do you have examples of leaders who have ingrained this in their daily work? What does this sound like? look like?" 
"My initial teaching experience was in a private school in Virginia. I came from that to high poverty/high risk schools in New Mexico. Just making that change made me see how much "privilege" affects school culture. In schools serving the underprivileged, many times the students are focused on surviving. They may face homelessness, parents who are not functional for many reasons, hunger, and complete insecurity in all ways."

"At times, even now I have interactions with people who teach in the higher-level socio-economically privileged schools. I have found that they don't always understand how much the playing field is not fair and equitable. And sadly, I have also seen some who, once made aware, just don't really care. They tend to 'other' schools, teachers, and students who are in this situation. 'We are great and they, over there, are failing.' It really hurts me at a deep level when I encounter that."
"I am wondering about your use of the word, underprivileged? What if you thought about this differently? For example, are students with deep cultural funds of knowledge actually 'underprivileged' or do their cultures 'privilege' them in ways that provide them with assets that their more 'privileged' peers don't have?"

"How have you responded in the past? How might you respond now? This journal entry tells me you have done your own deep reflection. Is there a reading you might suggest that could help our colleagues know how we are 'othered' or how we 'other' another?"

The instructor's interventions were designed to probe candidates' understanding of cultural competence and to prompt candidates to think more deeply about how they might apply their understandings in their journey to school leadership. Candidates reflected on their confidence and capacity to examine the implications and impacts of leading through the lens of cultural competence. After receiving feedback on their reflections, candidates noted that the definitions and indicators would provide a useful guide for implementing culturally rooted practices at their own sites.

A takeaway from the participants was the expressed need for more frequent opportunities to practice collaboration and to challenge deficit thinking during their pre-service preparation program. Faculty noted this could help them better determine where individuals, and/or groups of students, might need additional support, information, coaching or experiential opportunities to push the learning forward. Faculty observed that this would necessarily involve providing immediate feedback, observing students' interactions and intentionally examining how students negotiate, collaborate and demonstrate culturally proficient communications.

\section{Reflections and Next Steps}

The work of the interdisciplinary faculty to raise the cultural competence of candidates is ongoing. Faculty acknowledged that if they hope to see fundamental changes in schools, communities and systems, then more work needs to be done in teacher and leader preparation programs to create the capacity of the next generation of educators to advocate for equity and social justice.

A focus on reconnecting research, policy and practice to social justice and equity framed the work of faculty in collaboration with school and community members. Not all faculty were receptive to this kind of public-engaged work at first; however, more joined as they saw candidates engaged in building cultural competencies. Advancing the collective work required faculty skill in facilitating a common purpose through mutual respect, ongoing learning, and accountability. The desired outcome was to create a critical 
mass of like-minded scholars and practitioners who were committed to interrogating their own practices, revising their curricular decisions, willing to engage with stakeholders in meaningful, two-way interaction, and ready to counter all forms of stereotypes, silos and statuses that tend to perpetuate inequitable conditions.

Through the work of the redesign process faculty concluded that leadership resides in the community where everyone is responsible for honoring and empowering children's identities, languages, abilities, and cultures. Finally, faculty recommended that the work must be approached through praxis that is mindful and reflexive, grounded in place and space, responsive to multiple perspectives, and centered on learning rather than power and control.

\section{Further Research}

Further research is needed to demonstrate a clear rationale, based on promising evidence from welldesigned and well-implemented studies, that the activities and interventions are likely to improve the cultural competence of leaders. The redesign efforts from this study raised more questions than answers. For example, what are the barriers that inhibit culturally responsive practices among faculty who wrestle with making their practices inclusive (Ryan, 2006; Osta \& Perrow, 2008)? What curriculum and pedagogy will best foster sustained, scalable change? How might faculty support candidates to create more inclusive opportunities for differently-abled students, children of diverse sexual orientations, cultures and heritage languages, and those who have been marginalized by race and class? How can faculty quantify their impacts on candidates' cultural competence (Guskey, 2002)? How will faculty know if candidates are prepared to make the kinds of transformational changes that are needed to ensure every student succeeds?

Ongoing studies are needed to examine these and other questions. As the authors of Advancing Equity through ESSA contend, more work needs to be done to "Coordinate with educator preparation programs and professional development providers to ensure that future teachers and leaders are trained in culturally-responsive pedagogy, literacy development, positive behavioral supports, and other evidencebased interventions that can help engage students from a variety of backgrounds" (Authors, 2016, p. 12). ESSA opens the door to this work with targeted funds to support the academic achievement and wellbeing of diverse learners. Institutions of higher education can do more by providing effective teacher and principal preparation, effective professional development activities and other evidence-based approaches that will increase opportunities for historically marginalized students. Now is the time to exercise our collective will to redress inequitable outcomes and make opportunity equity a reality for all children. As Hillel the Elder famously said: If not now, when? 


\section{APPENDIX 1}

\section{Sample Completed Individual Reflection Sheet}

Do you agree with the proposed definition and key indicators of cultural competence?

$\mathrm{X} \quad$ If Yes, or to some extent, skip to $A$. If No, or to a limited extent, skip to $B$.

\section{A. (Yes). Please comment on the following. Expand the space as needed.}

1. Are any ideas in the definition or indicators overgeneralized, ambiguous or missing?

There was a need for clarification of some terms/concepts and the large group was able to thoughtfully and respectfully agree to edits.

2. Which of the ideas are most valuable to your own teaching, research, and/orcontinued professional learning?

All of the ideas, when operationalized, apply to my teaching with and from my students (I count learning from my students as continuous professional learning!) I have 4 open IRBs that connect with my teaching on issues of cultural competence/deeper learning.

3. How manageable would it be for you to include some of these ideas in your curriculum, pedagogy, and/or assessments of candidates' cultural competence?

Very manageable if I approach this as making changes in my courses one module at a time, one revised module per semester.

4. Which current course or courses do you believe best align with the proposed definition and indicators? This could include fieldwork.

I think we need to backward map again to make sure our Administrative Licensure courses are actually "covering" the proposed indicators.

\section{B. (No). Please comment on the following. Expand the space as needed.}

1. Are any ideas in the definition or indicators overgeneralized, ambiguous, or missing?

2. What ideas in the definition or indicators are out of your comfort zone?

3. For those ideas that are out of your level of comfort, what do you need to support your use of the definition and indicators in your curriculum, pedagogy, and/or assessments?

4. What would it take for you to go along with the proposed definition and indicators? 


\section{References}

Balfanz, R., \& Byrnes, V. (2012). The Importance of Being in School: A Report on Absenteeism in the Nation's Public Schools. Baltimore, MD: Johns Hopkins University Center for Social Organization of Schools. Retrieved from http://new.every1graduates.org/wpcontent/uploads/2012/05/FINALChronicAbsenteeismReport_May16.pdf

Blankstein, A. M., Noguera, P., Kelly, L., \& Tutu, D. (2015). Excellence through equity: Five principles of courageous leadership to guide achievement for every student. Thousand Oaks, CA: Corwin.

Boyd, J. (2008). Coaching in context. State of Victoria, Australia: Department of Education.

Cooper, C. W. (2009). Performing cultural work in demographically changing schools: Implications for expanding transformative leadership frameworks. Educational Administration Quarterly, 45(5), 694-724.

Costa, J. (2015). Preparing school leaders to advocate for social justice: A case analysis of social justice tenets in a leadership preparation program (WIDA Research Brief). Retrieved from www.wida.us/downloadLibrary.aspx

Every Student Succeeds Act (2015). U. S. Department of Education. Retrieved from https://www.gpo.gov/fdsys/pkg/BILLS-114s1177enr/pdf/BILLS-114s1177enr.pdf

Freire, P. (1998). Pedagogy of freedom: Ethics, democracy, and civic courage. New York, NY: Rowman \& Littlefield Publishers, Inc.

Garmston, R. J., \& Wellman, B. M. (1999). The adaptive school: A sourcebook for developing collaborative groups. Norwood, MA: Christopher-Gordon Publishers.

Gray, M. (2011). Back to basics: A critique of the strengths perspective in social work. Families in Society: The Journal of Contemporary Social Services, 92(1), 5-11. DOI: 10.1606/1044-3894.4054.

Guskey, T. R. (2002). Does it make a difference? Evaluating professional development. Educational Leadership, 59(6), 45-51.

Jensen, E. (2009). Teaching with poverty in mind: What being poor does to kids' brains and what schools can do about it. Alexandria, VA: ASCD.

Leadership Conference on Human Rights. (2016, August 1). Statement of 31 Civil and Human Rights and Education Groups on Draft ESSA Accountability Regulations. Retrieved from http://www.civilrights.org/press/2016/essa-accountability-regs.html

Morgan, E., Salomon, N., Plotkin, M., \& Cohen, R. (2014). The School Discipline Consensus Report: Strategies from the Field to Keep Students Engaged in School and Out of the Juvenile Justice System. New York, NY: Council of State Governments Justice Center. Retrieved from http://csgjusticecenter.org/youth/school-discipline-consensus-report/

National Policy Board for Educational Administration. (2015). Professional Standards for Educational Leaders. Reston, VA: Author.

Neufeld, B., \& Roper, D. (2003). Coaching: A strategy for developing instructional capacity. Providence, RI: Education Matters and Annenberg Institute for School Reform.

Osta, K., \& Perrow, M. (2008). Coaching for educational equity: The BayCES coaching Framework. San Francisco, CA: Bay Area Coalition for Equitable Schools. 
Ryan, J. (2006). Inclusive Leadership. San Francisco, CA: Jossey-Bass.

Saleh, A., McBride, J., \& Henley, J. (2006). Aspiring school leaders reflect on the internship. Academic Exchange Quarterly, 10(3).

Senge, P. M. (1994). The fifth discipline fieldbook: Strategies and tools for building a learning organization. New York, NY: Doubleday.

Shields, C. (2013). Transformative leadership in education: Equitable change in an uncertain and complex world. New York: Routledge.

Starratt, R. J. (1991), Building an ethical school: A theory for practice in educational leadership. Educational Administration Quarterly, 27(2),155-202.

The Aspen Education \& Society Program and the Council of Chief State School Officers. (2016). Advancing Equity through ESSA: Strategies for State Leaders. Retrieved from https://www.aspeninstitute.org/publications/advancing-equity-essa-strategies-state-leaders/

U. S. Commission on Civil Rights. (2018, January 10). Public education funding inequity in an era of increasing concentration of poverty and resegregation. Washington, D.C.: Briefing before the United States Commission on Civil Rights. Retrieved from http://www.usccr.gov/pubs/2018-0110-Education-Inequity.pdf

Valdez, T., \& Lugg, C. (2010). Community cultural wealth and Chicano/Latino students. Journal of School Public Relations, 31(3).

Yosso, T. J. (2005). Whose culture has capital? A critical race theory discussion of community cultural wealth. Race Ethnicity and Education, 8(1), 69-91.

\section{About the Author}

Dr. Sheri Williams (ssw@unm.edu) is an Assistant Professor in the Educational Leadership Program at the University of New Mexico. Williams joined the College of Education in 2013 and works with interdisciplinary scholars, policy makers, and practitioners on projects designed to reimagine the teaching and learning of aspiring school leaders. She engages with external evaluators on the assessment of innovative preparation programs for educational leadership. Her research centers on the preparation of instructional leaders in urban, tribal, and rural contexts for data-informed, socially just, and democratic leadership, with a focus on building cultural proficiency and mobilizing community to shape educational outcomes. She began her career as a high school teacher and completed 23 continuous years of administrative service as Superintendent of two rural school districts, Assistant Superintendent in a large urban district, and Principal of four rural schools. She has received numerous honors including the "Excellence in Education Award" from the National Alliance of Business and the "Friend of Education Award" from the Colorado Education Association. She was elected Vice President of the National PTA and held appointments on the National Advisory Panel for Child Care Action Campaign and the Sixth US Congressional District Education Task Force. She has served as a Board member for the North Central Association of Colleges and Schools and New Mexico Voices for Children. She is a fellow with NAESP. Williams was named to the UCEA Policy Team where she contributes to research on national education policy trends. She is a graduate of the 2007 International Aspen Ideas Institute and the 2011 Leadership New Mexico Core Program. Williams earned her B.A. from Colorado State University; M.A. from the University of Illinois; Ed.D. from Oklahoma State University; and an Executive Leadership Administrative Certificate from the University of Colorado. 